\title{
Rescue bedside laparotomy in the intensive care unit in patients too unstable for transport to the operating room
}

\author{
Joerg Schreiber ${ }^{1 \dagger}$, Axel Nierhaus ${ }^{1 *+}$, Eik Vettorazzi ${ }^{2}$, Stephan A Braune ${ }^{1}$, Daniel P Frings ${ }^{1}$, Yogesh Vashist $^{3}$,
} Jakob R Izbicki ${ }^{3}$ and Stefan Kluge ${ }^{1}$

\begin{abstract}
Introduction: The prognoses of critically ill patients with a requirement for emergency laparotomy and severe respiratory and/or hemodynamic instability precluding transport to the operating room (OR) are often fatal without surgery. Attempting emergency surgery at the bedside might equally result in an adverse outcome. However, risk factors and predictors that could support clinical decision making have not been identified so far. This study describes the clinical characteristics, indicative pathophysiology and outcomes in patients undergoing resuscitative laparotomy in the intensive care unit (ICU).

Methods: This was a retrospective observational study of all critically ill adult patients undergoing resuscitative laparotomy in the ICUs of a German university hospital from January 2005 to July 2013. Clinical characteristics, risk factors, and treatments were compared between survivors and non-survivors. The primary endpoint was 28-day survival.

Results: A total of 41 patients with a median age of 64 (21 to 83) were included. The most frequent reasons for ICU admission were sepsis, pneumonia, and pancreatic surgery. All patients were mechanically ventilated, receiving vasopressors, and were in multiple organ failure. Twenty-nine patients (70.7\%) were on renal replacement therapy and two patients (4.9\%) on extracorporeal membrane oxygenation. The main reasons for surgery were suspected intra-abdominal bleeding (39.0\%), suspected intestinal ischemia (24.4\%) or abdominal compartment syndrome (24.4\%). Twenty-eight-day, ICU and hospital mortalities were $75.6 \%, 80.5 \%$, and $82.9 \%$, respectively. In six out of ten patients (60\%) who survived surgery for more than 28 days, bedside laparotomy was rated as a life-saving procedure by an interdisciplinary group of the investigators.
\end{abstract}

Conclusions: These findings suggest that in selected critically ill patients with a vital indication for emergency laparotomy and severe cardiopulmonary instability precluding transport to the $\mathrm{OR}$, a bedside resuscitative laparotomy in the ICU can be considered as a rescue procedure, even though very high mortality is to be expected.

\section{Introduction}

In general, elective surgery is performed in specially equipped operating rooms (ORs). Optimal hygiene, lowering the rate of perioperative infections, the presence of specialized personnel, optimized lighting conditions and the availability of all essential surgical equipment and

\footnotetext{
*Correspondence: nierhaus@uke.de

†Equal contributors

'Department of Intensive Care Medicine, University Medical Center Hamburg-Eppendorf, Martinistr. 52, 20246 Hamburg, Germany

Full list of author information is available at the end of the article
}

infrastructure make the OR the optimal site for performing surgery [1].

It has been shown that some elective surgical procedures, such as tracheostomies [2,3], percutaneous endoscopic gastrostomy [4] and open lung biopsy [5] can be safely performed at the bedside in the intensive care unit (ICU). In such cases, avoiding transfer to the OR offers an advantage without any negative consequences. In patients with acute and life-threatening intra-abdominal conditions and vital indication for emergency laparotomy, but with severe hemodynamic and/or respiratory 
instability precluding safe transport to the OR, bedside rescue laparotomy in the ICU might be the only viable intervention [6]. Clinical scenarios necessitating emergency surgery include major uncontrollable intra-abdominal hemorrhage, acute intestinal ischemia or abdominal compartment syndrome (ACS) leading to and/or being caused by severe cardiopulmonary instability $[7,8]$.

At present there is only limited data on bedside emergency surgery outside the OR. Few studies have analyzed bedside laparoscopy in critically ill patients with acute abdomen $[9,10]$ or emergency thoracotomy in the emergency room $[11,12]$. Reports on resuscitative laparotomy in the ICU are scarce and have analyzed heterogeneous cohorts with respect to the degree of urgency (emergency and elective surgery) $[13,14]$ or with respect to the instability and the site of surgery (surgery in the ICU and in the OR) [15-18]. Attempting emergency surgery at the bedside might equally result in an adverse outcome. However, risk factors and predictors that could support clinical decision making have not been identified so far. Therefore, the aim of this study was to describe the clinical characteristics, pathophysiological indicators, and outcomes of a cohort of severely ill adult patients all too unstable for transport to the OR undergoing emergency bedside laparotomy as a vital indication in the ICU. We hypothesized that (1) in these patients, even though a very high mortality rate will be unavoidable, attempting emergency surgery is not futile, and (2) that we would be able to identify pathophysiological markers indicating poor outcome.

\section{Material and methods Study design}

This retrospective observational study included all adult critically ill patients treated in the Department of Intensive Care Medicine of the University Medical Center Hamburg-Eppendorf between January 2005 and July 2013 who underwent bedside resuscitative emergency laparotomy. The Department of Intensive Care Medicine at the University Medical Center Hamburg-Eppendorf, Germany, consists of 11 ICUs with a total of 132 beds and provides intensive care medicine to all adult patients in the university hospital. Approximately 7,000 patients are treated annually in the department (data from 2012). All patients were situated either in a single or two-bed room at the time of bedside surgery. Patients were included only if their highly compromised hemodynamic and/or respiratory state precluded a transfer from the ICU to the OR. This decision was reached by an interdisciplinary consensus by senior staff members in all cases if (1) the patient required more than $1.2 \mu \mathrm{g} / \mathrm{kg} / \mathrm{min}$ of norepinephrine, or (2) was on $100 \%$ oxygen with a positive end-expiratory pressure (PEEP) level of more than 14 mbar resulting in a fraction of inspired oxygen/arterial oxygen tension $\left(\mathrm{F}_{\mathrm{i}} \mathrm{O}_{2} / \mathrm{P}_{\mathrm{a}} \mathrm{O}_{2}\right)$ ratio below $150 \mathrm{mmHg}$ and a documented critical deterioration of oxygenation if derecruitment occurred, or (3) was on extracorporeal life support (extracorporeal membrane oxygenation (ECMO), intra-aortic balloon pump (IABP)). Patients who underwent elective bedside abdominal surgery as an exception due to internal logistic reasons like staff shortage in the OR were excluded, as were all ICU cases with bedside laparoscopy. Primary endpoint was 28-day survival.

Assessing the vital indication for emergency laparotomy and the risks of transport to the OR in these patients and performing a bedside resuscitative laparotomy in the ICU was a highly individualized and collective decisional process of the senior consultants of the Department of Intensive Care Medicine and the Department of Surgery.

The ethics committee of the Hamburg Chamber of Physicians approved the collection, analysis, and publication of the retrospectively obtained and anonymized data and waived the need to obtain informed consent for this non-interventional study.

\section{Data collection}

In January 2005, the Department of Intensive Care Medicine was founded at our University Medical Center, consisting of all adult ICU beds in the hospital. At the same time, a comprehensive patient data management system was installed, giving access to the complete medical record of the patients. For reasons of data quality and integrity we defined this point in time as the effective date to start the observation period.

From the electronic patient data management system (Integrated Care Manager ICM, Draeger Medical, Lübeck, Germany) the following data were obtained: demographics, clinical characteristics, laboratory findings, medications, simplified acute physiology score II (SAPS II), acute physiology and chronic health evaluation II (APACHE II) score, indications for emergency laparotomy, intraoperative findings, type and duration of surgery, surgery-related complications, and length of stay (LOS) in the ICU and in the hospital. To assess the effect of bedside surgery in the 28 -day survivors $(\mathrm{n}=10)$, all authors individually categorized surgery in the survivor cases as 'life-saving surgery', 'with unclear surgical impact on immediate survival', or 'without life-saving surgical impact'. The cases were analyzed taking into account diagnosis, intraoperative findings and the postoperative results. We discussed this in depth among the authors. In the case of disagreement (two cases) a consensus was reached through group discussion.

\section{Statistical analysis}

Continuous variables are expressed as medians (with range). Categorical variables are expressed as counts (and 
percentages). In order to compare the clinical characteristics and risk factors between survivors and non-survivors, non-parametric analyses were performed. Depending on the data type $\chi^{2}$ test, Fisher's exact test, or Mann-Whitney $U$ test were applied. A two-sided $P$ value of $<0.05$ was considered significant. Receiver operating characteristic area under the curve according to de Long was performed. The software used for analyses was IBM SPSS 20.0 (IBM Corp., Armonk, NY, USA).

\section{Results}

\section{Patient characteristics}

During the study period, 41 critically ill patients with a median age of 64 years underwent resuscitative bedside laparotomy in the ICU. Table 1 shows the cohort's clinical characteristics on ICU admission. The most frequent diagnoses leading to ICU admission were sepsis (24.4\%), pneumonia (14.6\%), and postoperative admission after pancreatic surgery $(12.2 \%)$.

At the time of resuscitative laparotomy all patients were mechanically ventilated with a median $\mathrm{PaO}_{2} / \mathrm{FiO}_{2}$ ratio of $136 \mathrm{mmHg}$ (33 to 559). The median dose of norepinephrine was 1.17 (0.02 to 11.33 ) $\mu \mathrm{g} / \mathrm{kg} / \mathrm{min}$. Thirtyseven patients $(90.2 \%)$ had acute renal failure and 29 (70.7\%) received renal replacement therapy; two patients (4.9\%) were on ECMO and one patient was treated with an IABP. Of the 41 patients, $20(48.7 \%)$ were ventilated with a $\mathrm{F}_{\mathrm{i}} \mathrm{O}_{2}$ of 1.0 and a PEEP level of above 14 mbar. Eighteen patients (44\%) received norepinephrine at a dose of above $1.2 \mu \mathrm{g} / \mathrm{kg} / \mathrm{min}$, three patients $(7.3 \%)$ had extracorporeal devices. Further clinical characteristics on the day of surgery are given in Table 2 .

\section{Surgical procedures}

The reasons for laparotomy were: suspected abdominal bleeding $(\mathrm{n}=16 ; 39 \%)$, suspected intestinal ischemia $(\mathrm{n}=10$; $24.4 \%)$, abdominal compartment syndrome $(\mathrm{n}=10 ; 24.4 \%)$ or a suspected intra-abdominal focus for sepsis $(n=5$; $12.2 \%)$. The 10 subjects with abdominal compartment

Table 1 Reasons for ICU admission

\begin{tabular}{lc}
\hline Diagnosis on admission & $\mathbf{n}(\%)$ \\
\hline Sepsis & $10(24)$ \\
Pneumonia & $6(15)$ \\
Pancreatic surgery & $5(12)$ \\
Liver transplantation & $4(10)$ \\
Intra-abdominal bleeding & $4(10)$ \\
CPR & $3(7)$ \\
ARDS & $2(5)$ \\
Trauma & $2(5)$ \\
Other & $5(12)$ \\
\hline
\end{tabular}

CPR, cardiopulmonary resuscitation; ARDS, acute respiratory distress syndrome. syndrome had an increased median abdominal pressure of $27 \mathrm{cmH}_{2} \mathrm{O}$ (range 20 to 180) as measured indirectly by determining intravesical pressure. The median duration of surgery was 40 minutes (10 to 190). In 33 $(80.5 \%)$ of the 41 cases the suspected diagnosis was confirmed intraoperatively, only five cases (12.2\%) yielded a negative result. Fourteen patients (34.1\%) required a subsequent surgical intervention in the OR and all of these patients had a temporary abdominal closure. Temporary closure was achieved by either the insertion of a Vicryl woven mesh or by vacuum-assisted closure (VAC). Seven patients (17.1\%) underwent a postmortem examination. All autopsy findings were in line with the suspected diagnoses and the surgical findings. No obvious major surgical complications, such as iatrogenic injury, uncontrollable bleeding, sepsis caused by wound infection, or death occurred in any of the 41 patients. Table 3 provides further details of the surgical procedures.

\section{Outcomes}

The 28 -day, ICU, and hospital mortality was $75.6 \%, 80.5 \%$, and $82.9 \%$, respectively. The median time from ICU admission to resuscitative laparotomy was three days $(0 / 56)$.

Table 2 shows the clinical characteristics of the 28-day survivors and non-survivors. No patient with a suspected diagnosis of intestinal ischemia $(n=10)$ survived. Non-survivors had significantly higher SAPS II and APACHE II scores, required significantly higher doses of norepinephrine, and had significantly lower $\mathrm{pH}$ and higher serum lactate values. No patient with lactate $>10.7 \mathrm{mmol} / \mathrm{l}$ or $\mathrm{pH}$ less than 7.21 survived. When calculating receiver operating characteristic area under the curve and the odds ratio for non-survival, it became evident that the variables indicating severe metabolic derangement and acidosis (base excess, lactate and $\mathrm{pH}$ ) had the highest predictive power (Table 4 ). Twenty-eight-day survivors $(24.4 \%)$ had higher median hemoglobin concentrations, but did not differ significantly from the non-survivors regarding the number of transfused red blood cell units 24 hours before and after surgery. There was no statistically significant difference between survivors and non-survivors regarding laboratory markers of inflammation or sepsis (white blood cell count, C-reactive protein and procalcitonin). Neither $\mathrm{P}_{\mathrm{a}} \mathrm{O}_{2} / \mathrm{F}_{\mathrm{i}} \mathrm{O}_{2}$ ratios nor arterial carbon dioxide tension $\left(\mathrm{P}_{\mathrm{a}} \mathrm{CO}_{2}\right)$ levels differed significantly between the groups.

Of the 10 patients who survived 28 days, the emergency surgery was considered a life-saving procedure in six cases $(60 \%)$ by the investigators. Two of these six patients required cardiopulmonary resuscitation within 24 hours before surgery.

\section{Discussion}

We report the clinical characteristics and outcomes of a cohort of 41 critically ill patients with severe multiorgan 
Table 2 Demographic and clinical data of survivors (at 28 days) and non-survivors

\begin{tabular}{|c|c|c|c|c|}
\hline & & $\begin{array}{c}\text { Survivors } \\
n=10(24.4 \%)\end{array}$ & $\begin{array}{l}\text { Non-survivors } \\
\mathrm{n}=31 \text { (75.6\%) }\end{array}$ & $P$ value \\
\hline \multicolumn{2}{|l|}{ Age } & $53.5(21-78)$ & $64(27-83)$ & 0.387 \\
\hline \multicolumn{2}{|l|}{ Sex (female/male) } & $6 / 60$ & $4 / 12.9$ & 0.006 \\
\hline \multicolumn{2}{|l|}{ SAPS II (ICU admission) } & $43(32-74)$ & $60(30-85)$ & 0.027 \\
\hline \multicolumn{2}{|l|}{ SAPS II (day of surgery) } & $44(33-72)$ & $67(41-83)$ & 0.001 \\
\hline \multicolumn{2}{|l|}{ APACHE II score (day of admission) } & $17(12-38)$ & $29(9-42)$ & 0.039 \\
\hline \multicolumn{2}{|l|}{ APACHE II score (day of surgery) } & $18(12-34)$ & $31(12-44)$ & 0.002 \\
\hline Time from ICU admission to surgery & days & $5(0-56)$ & $2(0-26)$ & 0.342 \\
\hline Length of stay in ICU post-op & days & $48(14-68)$ & & \\
\hline \multicolumn{5}{|l|}{ Laboratory data } \\
\hline Hemoglobin & $\mathrm{g} / \mathrm{dL}$ & $9.7(6.3-13,4)$ & $8.0(2.4-15.1)$ & 0.012 \\
\hline WBC & $\times 10^{3} / \mu \mathrm{L}$ & $13.1(1.0-85.5)$ & $13.6(0.3-32.2)$ & 0.832 \\
\hline Platelets & $\times 10^{3} / \mu \mathrm{L}$ & $119(34-405)$ & $62(12-620)$ & 0.202 \\
\hline \multicolumn{2}{|l|}{ International normalized ratio } & $1.29(1.03-2.46)$ & $1.49(0.96-3.43)$ & 0.208 \\
\hline Alanine aminotransferase & $I U / L$ & $45(6-1350)$ & $430(6-6936)$ & 0.024 \\
\hline Serum creatinine & mg/L & $1.31(0.4-2.4)$ & $1.7(0.8-7.7)$ & 0.060 \\
\hline C-reactive protein & mg/L & $56(10-337)$ & $115(<5-504)$ & 0.820 \\
\hline Procalcitonin & $\mu g / L$ & $3.63(0.2-263)$ & $7.4(0.93-292)$ & 0.896 \\
\hline Lactate & $\mathrm{mmol} / \mathrm{L}$ & $3.3(2.4-10.7)$ & $11.4(2.9-27.0)$ & $<0.001$ \\
\hline \multicolumn{2}{|l|}{$\mathrm{pH}$} & $7.31(7.21-7.47)$ & $7.14(6.87-7.51)$ & $<0.001$ \\
\hline Base excess & $\mathrm{mEq} / \mathrm{l}$ & $-1.0(-8.1-3.1)$ & $-13.1(-21.3-4.4)$ & $<0.001$ \\
\hline $\mathrm{S}_{\mathrm{CV}} \mathrm{O}_{2}$ & $\%$ & $74(63-84)$ & $71(38-86)$ & 0.436 \\
\hline \multicolumn{5}{|l|}{ Gas exchange } \\
\hline \multicolumn{5}{|l|}{ Mechanical ventilation } \\
\hline \multicolumn{2}{|l|}{$\mathrm{F}_{\mathrm{i}} \mathrm{O}_{2}$} & $0.85(0.3-1.0)$ & $0.9(0.3-1.0)$ & 0.923 \\
\hline $\mathrm{P}_{\mathrm{a}} \mathrm{O}_{2} / \mathrm{F}_{\mathrm{i}} \mathrm{O}_{2}$ ratio & $\mathrm{mmHg}$ & $171(33-503)$ & $129(49-559)$ & 0.835 \\
\hline $\mathrm{P}_{\mathrm{a}} \mathrm{CO}_{2}$ & $\mathrm{mmHg}$ & $51(33-67)$ & $48(29-90)$ & 0.821 \\
\hline \multicolumn{5}{|l|}{ Renal situation } \\
\hline \multicolumn{2}{|l|}{ Acute renal failure } & $10(100 \%)$ & $27(87.1 \%)$ & 1.0 \\
\hline \multicolumn{2}{|l|}{ Renal replacement therapy } & $8(80 \%)$ & $21(77.4 \%)$ & 0.725 \\
\hline \multicolumn{5}{|l|}{ Circulation } \\
\hline \multicolumn{5}{|l|}{ Vasopressor } \\
\hline \multicolumn{2}{|l|}{ Norepinephrine $\mathrm{mcg} / \mathrm{kg} / \mathrm{min}$} & $0.6(0.02-1.88)$ & $1.37(0.12-11.3)$ & 0.039 \\
\hline \multicolumn{2}{|l|}{ IABP } & & & 1.0 \\
\hline \multicolumn{2}{|l|}{ Surgery } & $0(0 \%)$ & $1(3.2 \%)$ & \\
\hline Duration of surgery & minutes & & & 0.553 \\
\hline \multicolumn{2}{|l|}{ Transfusion } & $45(19-190)$ & $40(10-92)$ & \\
\hline \multicolumn{2}{|c|}{ Number of red cell transfusions $24 \mathrm{~h}$ pre-op } & $1(0-6)$ & $2(0-105)$ & 0.253 \\
\hline \multicolumn{2}{|c|}{ Number of red cell transfusions intra/24 h post-op } & $3(0-12)$ & $4(0-50)$ & 0.535 \\
\hline
\end{tabular}

Values given as median (range) or number (\%); $P$ values from Mann-Whitney $U$ test for continuous data, Fisher's exact test is used for categorical data. SAPS II, simplified acute physiology score II; APACHE II, acute physiology and chronic health evaluation II; WBC, white blood cell count; $\mathrm{S}_{\mathrm{cv}} \mathrm{O}_{2}$, central venous oxygen saturation; $\mathrm{F}_{\mathrm{i}} \mathrm{O}_{2}$, fraction of inspired oxygen; $\mathrm{P}_{\mathrm{a}} \mathrm{O}_{2}$, arterial oxygen tension; $\mathrm{P}_{\mathrm{a}} \mathrm{CO}_{2}$, arterial carbon dioxide tension; ECMO, extracorporeal membrane oxygenation; IABP, intra-aortic balloon pump; pre-op, preoperative; post-op, postoperative. 
Table 3 Suspected and intraoperative diagnoses, surgical procedures

\begin{tabular}{|c|c|}
\hline Indication for surgery/suspected diagnosis & n (\%) \\
\hline Intra-abdominal bleeding & $16(39.0)$ \\
\hline Intestinal ischemia & $10(24.4)$ \\
\hline Abdominal compartment syndrome & $10(24.4)$ \\
\hline Abdominal focus of sepsis & $5(12.2)$ \\
\hline \multicolumn{2}{|l|}{ Intraoperative diagnosis } \\
\hline Intra-abdominal bleeding & $17(41.5)$ \\
\hline diffuse bleeding & 7 \\
\hline $\begin{array}{l}\text { venous bleeding (mesenteric vein; portal vein; } \\
\text { gastric vein, vena cava) }\end{array}$ & 4 \\
\hline hepatic bleeding & 2 \\
\hline arterial bleeding (gastroduodenal artery; aorta) & 2 \\
\hline vascular anastomotic repair bleeding & 2 \\
\hline Intestinal ischemia & $9(22.0)$ \\
\hline Abdominal compartment syndrome & $8(19.5)$ \\
\hline Anastomotic breakdown & $2(4.9)$ \\
\hline Negative finding & $5(12.2)$ \\
\hline Patients needing subsequent surgery in $O R$ & $14(34.1)$ \\
\hline \multicolumn{2}{|l|}{ Surgical procedures } \\
\hline Surgical control of bleeding & $11(26.8)$ \\
\hline Decompressive laparotomy & $10(24.4)$ \\
\hline Packing & $8(19.5)$ \\
\hline Vascular repair & $3(7.3)$ \\
\hline Intestinal resection & $9(21.9)$ \\
\hline Peritoneal lavage, focus control & $5(7.3)$ \\
\hline
\end{tabular}

failure who underwent resuscitative bedside laparotomy for vital indications. Emergency surgery was performed in the ICU because these patients were considered too unstable for transport to the OR and their short-term prognosis was deemed lethal without emergency surgery. No relevant surgically related complications were observed.

Table 4 Receiver operating characteristic and odds ratio for non-survival

\begin{tabular}{lcc}
\hline Parameter & $\begin{array}{c}\text { ROC-AUC } \\
\mathbf{( 9 5 \% ~ C I )}\end{array}$ & $\begin{array}{c}\text { Odds ratio } \\
(\mathbf{9 5 \%} \mathbf{~ C I})\end{array}$ \\
\hline Base excess & $0.92(0.83,1.00)$ & $70(6.3,777.87)^{1}$ \\
Lactate & $0.92(0.82,1.00)$ & $56.25(5.53,572.39)^{2}$ \\
pH & $0.85(0.74,0.97)$ & $15.75(2.84,87.24)^{3}$ \\
SAPS II (day of surgery) & $0.84(0.68,1.00)$ & $8(1.62,39.3)^{4}$ \\
APACHE II (day of surgery) & $0.82(0.67,0.98)$ & $1.18(1.05,1.32)^{5}$ \\
Norepinephrine (mcg/kg/min) & $0.78(0.62,0.94)$ & $3(0.69,13.1)^{6}$ \\
\hline
\end{tabular}

Base excess <2 mEq/l; lactate $>5 \mathrm{mmol} / \mathrm{l}$; $\mathrm{pH}<7.3$; SAPS II $>55$; APACHE II $>25$; norepinephrine dose $>1 \mu \mathrm{g} / \mathrm{kg} / \mathrm{min}$. ROC-AUC, receiver operating characteristic area under the curve with confidence interval (CI) according to de Long; SAPS II, simplified acute physiology score II; APACHE II, acute physiology and chronic health evaluation II.
For a variety of reasons, the ICU is increasingly being used as a place for surgical procedures that were traditionally done in the OR [19]. Examples of (semi-)elective bedside surgery are the percutaneous dilatational tracheostomy [20] and percutaneous endoscopic gastrostomy [21]. Many surgical centers increasingly perform routine laparotomies in critically ill patients [22].

Laparoscopy is another surgical procedure that has been reported to be performed at the bedside in ICU in patients with acute abdomen $[10,23,24]$. A recent study on 62 critically ill patients showed bedside laparoscopy to be useful for obtaining a diagnosis in patients with acute abdomen [9]. However, in cases with positive findings (69\%), all patients had sufficient cardiopulmonary stability for transfer to the OR where they eventually underwent open surgery. Bedside laparoscopy, although less invasive than open surgery, not only has therapeutic but also diagnostic limitations. Early stages of mesenteric ischemia are difficult to verify and the sensitivity for retroperitoneal pathology is low $[9,10]$. Moreover, in the case of highly urgent surgery, for example for acute bleeding, setting up a laparoscopy is often too timeconsuming and therefore not an adequate approach. Another limitation is capnoperitoneum potentially further compromising the hemodynamics of already unstable patients.

As opposed to elective surgery, bedside resuscitative laparotomy in the ICU is considered as a heroic procedure' for patients who are in extremis and not transferable to the OR. Thus data for emergency laparotomies outside the OR are scarce and mostly refer to decompressive laparotomy in refractory ACS, for example in burns patients [15] or in trauma patients $[13,14,25]$. Unlike emergency bedside laparotomy, there are good data for emergency laparotomy in the OR, especially regarding the outcome of patients [8]. In a large cohort of critically ill patients who underwent emergency laparotomy, the mortality was $30.7 \%$, but these patients were stable enough to be operated in the OR with only postoperative ICU admission [26]. Using a protocol for bedside laparotomy Diaz et al. described 60 [14] and 75 [13] patients who underwent bedside laparotomy in a trauma ICU. Mortality rates were $23.3 \%$ and $49 \%$, respectively and the authors concluded that bedside laparotomy is feasible, safe, and carries an acceptable risk of complications and death considering the severity of illness of these patients. However, these studies mainly included trauma patients who underwent both elective surgical procedures (peritoneal lavage, closure of abdomen) as well as emergency procedures.

Lund et al. explored the outcome of trauma patients with hypovolemic shock who underwent emergency laparotomy in the emergency room due to hemodynamic instability [27]. The 30-day mortality rate of 44 patients with 
penetrating or blunt abdominal trauma was $59 \%$. Struck et al. recently reported on a cohort of 35 burns patients with ACS undergoing emergency laparotomy [15]. Overall mortality was $71.4 \%$, but only six patients underwent a bedside laparotomy in the ICU. Despite similar overall mortality rates, all 41 patients in our cohort were considered too unstable for transport.

Apart from the Struck et al. study, the 28-day mortality rate of $75.6 \%$ in our cohort of 41 patients undergoing resuscitative bedside laparotomy was higher than in the other above mentioned studies. The most likely reason for this is the greater severity of illness in our cohort. All previous studies on laparotomy in the ICU were in trauma patients, who are highly underrepresented in our cohort. By the day of ICU admission the median SAPS II of our cohort was already as high as 58 with a predicted mortality of $64.0 \%$ [28], similar to the mortality of $60.5 \%$ predicted from the median APACHE II score of 27 [29]. In addition, during the course in ICU their clinical state further deteriorated due to progressive multiorgan failure and/or secondary complications, subsequently increasing their mortality risk. This explanation is underlined by the fact that within 24 hours of requiring emergency surgery the SAPS II and APACHE II score increased and as many as 13 patients (31.7\%) required cardiopulmonary resuscitation.

One aim of our study was to identify predictive factors for survival after resuscitative bedside laparotomy. As one would expect, severe metabolic derangements were most predictive for adverse outcome. We found that no patient with intestinal ischemia, with lactate $>10.7 \mathrm{mmol} / \mathrm{l}$ or $\mathrm{pH}<7.21$ survived. Accordingly, the markers of metabolic acidosis showed the highest odds ratios for nonsurvival (Table 4). However, due to our small sample size we do not suggest that diagnosis of intestinal ischemia or certain laboratory values should be used to exclude patients for resuscitative bedside surgery.

At the time of surgery, all of our critically ill patients were unable to communicate, making a meaningful physical examination of the abdomen or thorax difficult. Unlike readily performed bedside procedures, such as laboratory tests, ultrasound or plain X-rays, more complex imaging techniques, such as computer and/or magnetic resonance tomography necessitate transfer out of the ICU. By definition, all of our patients were considered to have insufficient cardiopulmonary stability for any transfer and had a presumed fatal prognosis without surgery. The decision to perform immediate and resuscitative laparotomy in the ICU was not based on any standard operating procedures but on a highly individualized joint decision of the senior consultants of the Department of Intensive Care and the Department of Surgery.

Our study has some methodological limitations, which mainly arise from its design. First, the interpretation of the results is limited by potential biases introduced by the retrospective analysis and the inherent methodological lack of a control group in this type of clinical scenario. Ethical considerations and critical timing in emergency situations probably preclude the performance of randomized trials in this very challenging setting. However, we postulate that severe and life-threatening complications, because of their clinical impact, were most likely fully documented at the time of occurrence and detected during data acquisition. Second, the rare but severe clinical scenario limits the sample size despite the long study period. Finally, we cannot assess how many patients in a similar clinical scenario, who were not operated on and who subsequently died, could potentially have been saved by an emergency bedside laparotomy.

\section{Conclusions}

The results of our study suggest that in extreme situations with a vital indication for emergency laparotomy but severe cardiopulmonary instability preventing transport to the OR a rescue laparotomy in the ICU should be considered as a potential treatment option as a last resort. This applies especially to cases where death is imminent without immediate surgery.

\section{Key messages}

- Some critically ill patients are highly cardiopulmonary instable, precluding transport to the OR.

- In selected critically ill patients with a vital indication for emergency laparotomy and severe cardiopulmonary instability, precluding transport to the OR, a bedside rescue laparotomy in the ICU can be considered even though it is associated with a very high mortality, especially in patients with a profound metabolic acidosis.

\section{Abbreviations}

ACS: abdominal compartment syndrome; APACHE: acute physiology and chronic health evaluation; ECMO: extracorporeal membrane oxygenation; $\mathrm{F}_{\mathrm{i}} \mathrm{O}_{2}$ : fraction of inspired oxygen; IABP: intra-aortic balloon pump; ICU: intensive care unit; LOS: length of stay; OR: operating room;

$\mathrm{P}_{\mathrm{a}} \mathrm{O}_{2}$ : arterial oxygen tension; $\mathrm{P}_{\mathrm{a}} \mathrm{CO}_{2}$ : arterial carbon dioxide tension; PEEP: positive end-expiratory pressure; SAPS: simplified acute physiology score; VAC: vacuum-assisted closure.

\section{Competing interests}

The authors declare that they have no competing interests.

\section{Authors' contributions}

JS, AN, SB and SK have made substantial contributions to conception and design of the study as well as to the acquisition, analysis and interpretation of data. AN, DF, YV and JI have revised it critically for important intellectual content and have made substantial contributions to analysis and interpretation of data. EV has revised the statistical results and added important statistical content. JS, AN, SB and SK have drafted the submitted manuscript. AN has edited, revised and partially rewritten the manuscript. All authors read and approved the final manuscript. 


\section{Funding}

This work was funded exclusively by internal resources of the Department of Intensive Care Medicine.

\section{Author details}

'Department of Intensive Care Medicine, University Medical Center Hamburg-Eppendorf, Martinistr. 52, 20246 Hamburg, Germany. ${ }^{2}$ Institute for Biometry and Epidemiology, University Medical Center Hamburg-Eppendorf, Martinistr. 52, 20246 Hamburg, Germany. ${ }^{3}$ Department of General, Visceral and Thoracic Surgery, University Medical Center Hamburg-Eppendorf, Martinistr. 52, 20246 Hamburg, Germany.

Received: 1 January 2014 Accepted: 2 June 2014

Published: 16 June 2014

\section{References}

1. Van Beuzekom M, Boer F, Akerboom S, Hudson P: Patient safety in the operating room: an intervention study on latent risk factors. BMC Surg 2012, 12:10

2. Auzinger G, O'Callaghan GP, Bernal W, Sizer E, Wendon JA: Percutaneous tracheostomy in patients with severe liver disease and a high incidence of refractory coagulopathy: a prospective trial. Crit Care 2007, 11:R110.

3. Yoo DB, Schiff BA, Martz S, Fraioli RE, Smith RV, Kvetan V, Fried MP: Open bedside tracheotomy: Impact on patient care and patient safety. Laryngoscope 2011, 121:515-520.

4. Yarmus L, Gilbert C, Lechtzin N, Imad M, Ernst A, Feller-Kopman D: Safety and feasibility of interventional pulmonologists performing bedside percutaneous endoscopic gastrostomy tube placement. Chest 2013, 144:436-440.

5. Baumann HJ, Kluge S, Balke L, Yekebas E, Izbicki JR, Amthor M, Kreymann G, Meyer A: Yield and safety of bedside open lung biopsy in mechanically ventilated patients with acute lung injury or acute respiratory distress syndrome. Surgery 2008, 143:426-433.

6. An G, West MA: Abdominal compartment syndrome: a concise clinical review. Crit Care Med 2008, 36:1304-1310

7. Kirkpatrick AW, Roberts DJ, Waele J, Jaeschke R, Mailbrain ML, De Keulenaer B, Duchesne J, Bjorck M, Leppaniemi A, Ejike JC, Sugrue M, Cheatham M, Ivatury R, Ball CG, Reintam Blaser A, Regli A, Balogh ZJ, D'Amours S, Debergh D, Kaplan M, Kimball E, Olvera C: Intra-abdominal hypertension and the abdominal compartment syndrome: updated consensus definitions and clinical practice guidelines from the World Society of the Abdominal Compartment Syndrome. Intensive Care Med 2013, 39:1 190-1206.

8. de Waele J, Hoste E, Malbrain M: Decompressive laparotomy for abdominal compartment syndrome - a critical analysis. Crit Care 2006, 10:R51.

9. Ceribelli C, Adami EA, Mattia S, Benini B: Bedside diagnostic laparoscopy for critically ill patients: a retrospective study of 62 patients. Surg Endosc 2012, 26:3612-3615.

10. Gagné DJ, Malay MB, Hogle NJ, Fowler DL: Bedside diagnostic minilaparoscopy in the intensive care patient. Surgery 2002, 131:491-496.

11. Gomez G, Fecher A, Joy T, Pardo I, Jacobson L, Kemp H: Optimizing outcomes in emergency room thoracotomy: a 20-year experience in an urban Level I trauma center. Am Surg 2010, 76:406-410.

12. Lustenberger T, Labler L, Stover JF, Keel MJ: Resuscitative emergency thoracotomy in a Swiss trauma centre. Br J Surg 2012, 99:541-548.

13. Diaz JJ, Mauer A, May AK, Miller R, Guy JS, Morris JA Jr: Bedside laparotomy for trauma: are there risks? Surg Infect (Larchmt) 2004, 5:15-20.

14. Diaz JJ, Mejia V, Subhawong AP, Subhawong T, Miller RS, O'Neill PJ, Morris JA Jr: Protocol for bedside laparotomy in trauma and emergency general surgery: a low return to the operating room. Am Surg 2005, 71:986-991.

15. Struck MF, Reske AW, Schmidt T, Hilbert P, Stehen M, Wrigge H: Respiratory functions of burn patients undergoing decompressive laparotomy due to secondary abdominal compartment syndrome. Burns 2014, 40:120-126.

16. Boone B, Zureikat A, Hughes SJ, Moser AJ, Yadav D, Zeh HJ, Lee KK: Abdominal compartment syndrome is an early, lethal complication of acute pancreatitis. Am Surg 2013, 79:601-607.

17. Mayberry JC, Welker KJ, Goldman RK, Mullins RJ: Mechanism of acute ascites formation after trauma resuscitation. Arch Surg 2003, 138:773-776.

18. Biffl WL, Moore EE, Burch JM, Offner PJ, Franciose RJ, Johnson JL: Secondary abdominal compartment syndrome is a highly lethal event. Am J Surg 2011, 182:645-648.
19. Britt LD, Trunkey DD, Feliciano DV: Acute care surgery. New York, London: Springer; 2007

20. Kluge S, Baumann HJ, Maier C, Klose H, Meyer A, Nierhaus A, Kreymann G: Tracheostomy in the intensive care unit: a nationwide survey. Anesth Analg 2008, 107:1639-1643.

21. Van Natta TL, Morris JA Jr, Eddy VA, Nunn CR, Rutherford EJ, Neuzil D, Jenkins JM, Bass JG: Elective bedside surgery in critically injured patients is safe and cost-effective. Ann Surg 1998, 227:618-624.

22. Piper GL, Maerz LL, Schuster KM, Maung AA, Luckianow GM, Davis KA, Kaplan LJ: When the ICU is the operating room. J Trauma Acute Care Surg 2013, 74:871-875.

23. Jaramillo EJ, Treviño JM, Berghoff KR, Franklin ME Jr: Bedside diagnostic laparoscopy in the intensive care unit: a 13-year experience. JSLS 2006, 10:155-159

24. Karasakalides A, Triantafillidou S, Anthimidis G, Ganas E, Mihalopoulou E, Lagonidis D, Nakos $G$ : The use of bedside diagnostic laparoscopy in the intensive care unit. J Laparoendosc Adv Surg Tech A 2009, 19:333-338.

25. Ivatury RR, Porter JM, Simon RJ, Islam S, John R, Stahl WM: Intra-abdominal hypertension after life-threatening penetrating abdominal trauma: prophylaxis, incidence, and clinical relevance to gastric mucosal pH and abdominal compartment syndrome. J Trauma 1998, 44:1016-1021. discussion 1021-3.

26. Saunders DI, Murray D, Pichel AC, Varley S, Peden CJ: Variations in mortality after emergency laparotomy: the first report of the UK Emergency Laparotomy Network. Br J Anaesth 2012, 109:368-375.

27. Lund H, Kofoed SC, Hillingso JG, Falck-Larsen C, Svendsen LB: High mortality after emergency room laparotomy in haemodynamically unstable trauma patients. Dan Med Bull 2011, 58:A4275.

28. Le Gall J, Lemeshow S, Saulnier F: A new simplified acute physiology score (SAPS II) based on a European/North American multicenter study. JAMA 1993, 270:2957-2963.

29. Knaus WA, Draper EA, Wagner DP, Zimmermann JE: APACHE II: a severity of disease classification system. Crit Care Med 1985, 13:818-829.

\section{doi:10.1186/cc13925}

Cite this article as: Schreiber et al:: Rescue bedside laparotomy in the intensive care unit in patients too unstable for transport to the operating room. Critical Care 2014 18:R123.

\section{Submit your next manuscript to BioMed Central and take full advantage of:}

- Convenient online submission

- Thorough peer review

- No space constraints or color figure charges

- Immediate publication on acceptance

- Inclusion in PubMed, CAS, Scopus and Google Scholar

- Research which is freely available for redistribution 